\title{
5. Differentials and determinants of Indigenous population mobility
}

\section{John Taylor and Yohannes Kinfu}

Of the three components of demographic change, geographic mobility is the most nebulous and difficult to measure, and yet it is the one with potentially the greatest impact on population distribution and composition. Difficulties of measurement arise because a variety of definitions of population movement can be construed, all of which constitute arbitrary functions of the distance and length of time involved in relocating from one place to another. Impacts on distribution arise because migrant numbers in and out of a given place could exceed births and deaths, especially in small geographic areas and at higher stages of demographic transition, while age and sex selectivity of migration places a wide ranging effect on the composition of migrant sending-and-receiving regions.

In illuminating these issues, analysis of population movement for both the Indigenous and total Australian population has generally been informed by data yielded from fixed-period usual residence questions in the national census (that is, usual residence now compared to one and five years ago), as well as by information from case studies focused on particular localities or sub-populations (Bell 1992; Bell \& Maher 1995; Gale 1972; Gale \& Wundersitz 1982; Kinfu 2005; Taylor \& Bell 1996a). Admittedly, between 1970 and 1987, the ABS also conducted an annual survey of internal migration in conjunction with one of its monthly population surveys (without an Indigenous identifier) (ABS 1987). However, since that time, few official nationwide surveys have included a mobility indicator in Australia. Even those that have included a mobility indicator do not have an Indigenous identifier or have limited Indigenous samples (such as the Australian Housing Survey and the February supplement of the Labour Force Survey on labour mobility).

To this extent, the inclusion of a question on mobility status and reasons for movement in the 2002 NATSISS was a rare event and it presents two new opportunities for analysts. Firstly, it provides a new source of data with which to validate previous findings from census analysis and case studies. Secondly, the existence of wide ranging individual and household characteristics data allows for testing of the statistical relationship between these variables and mobility, thereby enabling a wider and more direct exploration of the social and economic determinants of movement than hitherto possible. The purpose of this chapter is, therefore, to make use of the survey data to examine the intensity and correlates of spatial mobility among Indigenous Australians. The 
distinguishing feature is that the determinants of mobility are explored from a micro rather a macro perspective, while reasons provided by respondents for their movement are also explored-something that has only previously been established indirectly by proximate cause using census data (Kinfu 2005).

\section{Background: survey development and questions}

Interestingly, the background to the inclusion of mobility questions in the 2002 NATSISS appears to be exactly the opposite to the experience of the 1994 NATSIS. In consultations before the 1994 survey, the topic of 'location and mobility' was proposed as important for inclusion by a number of government agencies under the broad heading of 'culture'. In particular, it was felt necessary to acquire data on the movement patterns of household members over a 12-month period before the survey, including the number of moves, duration of each move and reasons for each move. This mobility history was deemed by agencies such as ATSIC, Department of Employment, Education and Training (DEET), and the Department of Health, Housing and Community Services to be of assistance in planning the location of appropriate services such as community infrastructure and social programs. However, due to recall problems, less than adequate responses to mobility questions were obtained in the pilot survey and it was determined that an improvement in data quality would require overly-indulgent in-depth probing on an already crowded interview schedule. This led to the mobility questions being omitted, with the exception of a question on the number of moves away from the local area for the treatment of health problems (Taylor 1996: 41).

By contrast, in the preparations for the 2002 survey round, questions on mobility were initially excluded in line with 1994 practice. However, they were then included following strong user demand for inclusion, as mobility was viewed as a cross-cutting issue that impacted on many areas of concern (including health, education, employment and housing). While this view of the policy significance of mobility is widely held and articulated, what are less clear are the precise policy questions to be addressed by an understanding and measurement of movement. In short, what is it about mobility that we want to know and can a sample survey, such as the NATSISS, provide the answer?

The decision to include mobility questions turned out to be easier than deciding how to formulate appropriate questions. At the census, and in the now defunct ABS internal migration survey, people are classified as having moved if the address of their usual place of residence was different from that of one year or five years ago. In the 2002 NATSISS, the definition of movement is far more inclusive and refers to all moves made over the 12 months before the survey. In particular, the NATSISS asked (in non-remote and remote non-community sample areas), 'In the last 12 months, have you lived (emphasis added) in any other dwellings?' and (in remote community sample areas), 'In the last year have you 
lived (emphasis added) in any other houses or places?'. In both areas, the survey then went on to elicit how many dwellings, houses/places people had lived in over the course of the year.

Why these differences in the nature of questions deployed on community sample and non-community sample forms arose is not known. However, leaving this aside, the key point to note is that the probability of movement should be considerably higher in the 2002 NATSISS compared to the census, given its reference to all moves as opposed to a single specific move as defined by the fixed-period census 'usual residence' question. This lack of any temporal or spatial reference in framing the NATSISS definition of mobility is unusual, since duration and distance of movement are two key variables for mobility analysis (Bell 2001; Taylor \& Bell 2005). As mentioned earlier, the NATSISS also collected information on the main reason for the last move and classified these under four major headings: family, housing, employment and accessibility (to services). The issue of whether these questions provide an adequate and meaningful basis for addressing key policy issues - either independently or in association with other survey variables - will be dealt with in conclusion.

\section{The scale and age pattern of mobility}

Overall, 30.9 per cent of respondents to the NATSISS aged 15 years and over indicated that they had moved to live in another dwelling/house/place in the 12 months before the survey, with the true value (at the $95 \%$ confidence level) lying somewhere between 28.9 and 32.9 per cent. In light of the comments made above about the inclusive nature of the survey question, this is a surprisingly low proportion. This is especially true when benchmarked against 1996 and 2001 census results that show broadly similar propensities for movement for the same age group (29\% and $26 \%$ ) for the periods $1995-96$ and $2000-01$ respectively. Equally surprising, given the open-ended nature of the NATSISS mobility question, is that only a quarter of respondents who moved reported making more than one move over the 12 months before the survey.

Like all other demographic processes, change of residence is associated with age and certain life-cycle statuses and transitions (Long 1992). To investigate the age pattern of migration, Figure 5.1 compares age-specific movement rates from the NATSISS with equivalent rates derived from the 1996 and 2001 censuses. Clearly, the age pattern of movement derived from the NATSISS is in broad agreement with census results, in so far as movement comes to a peak among young adults aged 20-24 years and steadily declines thereafter. Overall, these patterns conform with more or less universal observations first made by Rogers, Raquillet \& Castro (1978) and Rogers \& Castro (1981) for the United States and Europe, and subsequently in the Australian context by Bell (1992, 1995). Basically, for the Australian population as a whole, as in other countries, the peak in the age profile of mobility has been linked to the combined influence 
of departure from the parental home, the start of tertiary education, entry into the labour force and the establishment of independent living arrangements. To the extent that Indigenous people participate in these same life-course events, the age profile of Indigenous movement is likely to reflect similar influences. In the subsequent section, we examine the gross and net effects of such variables on movement propensity.

\section{Figure 5.1. Age-specific Indigenous movement rates: 1996 Census, 2001 Census and 2002 NATSISS}

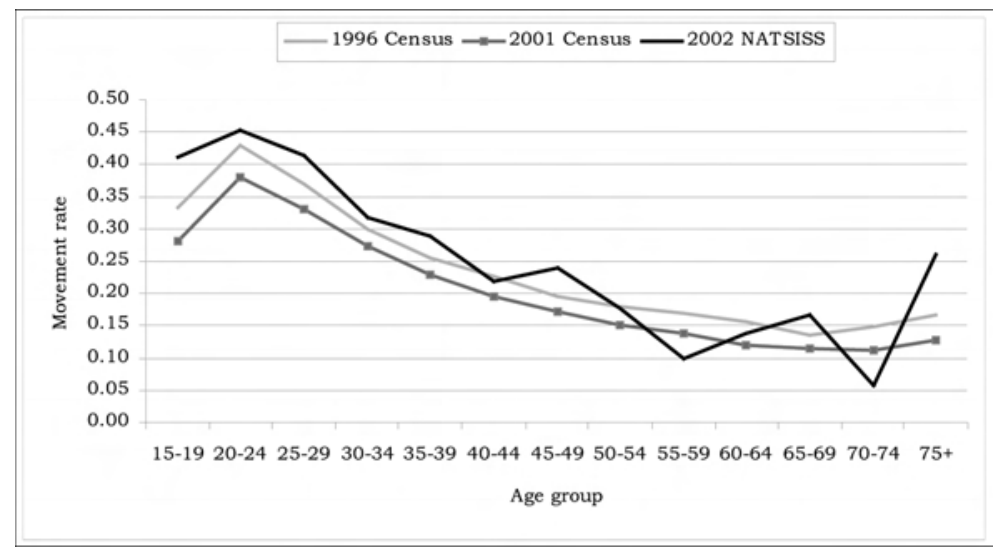

Source: Customised cross-tabulations.

What Figure 5.1 shows is that mobility rates derived from NATSISS are consistently higher than census rates (especially 2001 Census rates) up to age 50 , beyond which point the NATSISS pattern becomes relatively erratic, possibly due to the small sample size. Reading these sets of rates together, perhaps the more interesting observation is the consistent reduction in age-specific movement rates between the 1996 and 2001 censuses and the apparent increase from the 2002 NATSISS. This appears to be similar to other systematic shifts in Indigenous demographic indicators revealed by census analysis that are difficult to reconcile with demographic behaviour (Kinfu \& Taylor 2005).

\section{Differentials and determinants of mobility}

As with age, mobility also varies according to the geographic, socioeconomic and demographic characteristics of individuals and households. One limiting factor of the NATSISS in regard to establishing the geography of mobility and its demographic impact on sending and receiving regions is the lack of any origin/destination data. Instead, we have measures of the propensity to move (or not) at fairly large geographic units, notably States and the Northern Territory and the broad remoteness categories of the ASGC. For the most part, no difference is evident between jurisdictions in the propensity to move, given the spread of the upper and lower bounds of most estimates (see Fig. 5.2). However, stand-out 
exceptions include Tasmania and the Northern Territory, with the rate of movement in the latter ranging from as low as 15.7 per cent to no more than 20.9 per cent. In effect, the propensity to move among Indigenous people in the Northern Territory is only half the rate in Queensland. As for movement propensity by remoteness category, this reveals that inner regional areas display significantly higher mobility than all other regions except for major cities, while at the other extreme of the remoteness classification, the population in very remote areas displays significantly lower movement than all other regions.

Figure 5.2. Indigenous movement propensities by State and Territory, 2002

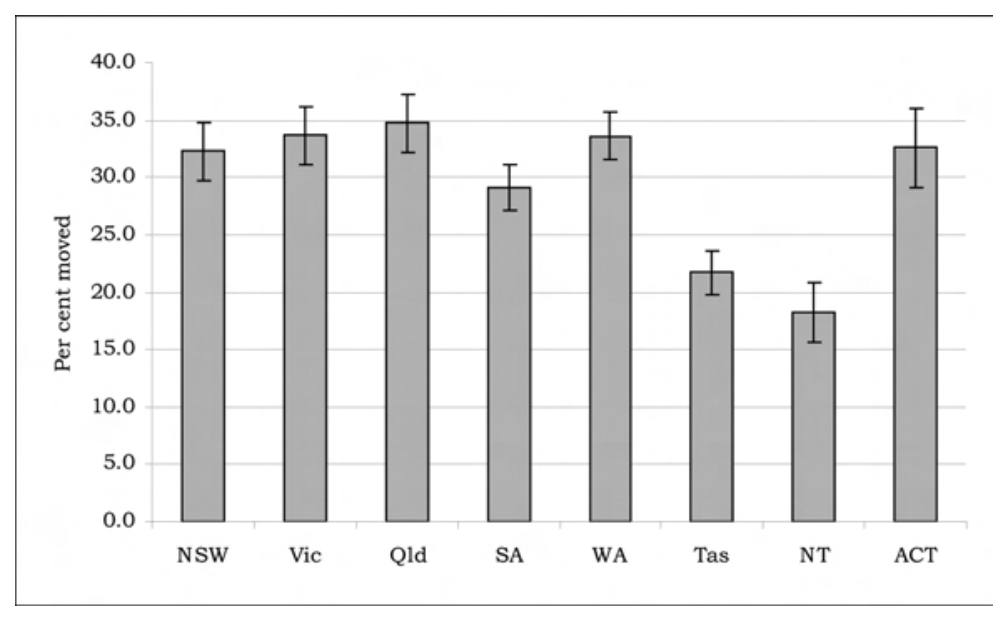

Source: Customised cross-tabulations.

These observations regarding the spatial pattern of movement are interesting for their similarity to consistent findings from census data that display the lowest rates of Indigenous mobility in remote areas of the north and west of the continent, and especially across the Northern Territory (Taylor \& Bell 1996b). This impression of relative immobility among Indigenous people in very remote areas and across the Northern Territory is grossly misleading. Numerous case studies attest to the importance of frequent mobility in the daily, periodic and seasonal round of activities associated with Indigenous social and economic life in such places (see Taylor \& Bell 2004 for a summary). The gap between these observations and NATSISS results is all the more surprising given the more inclusive nature of the NATSISS mobility question allowing for all moves to be recorded. This differs from the census question which is ill-suited to capturing the frequent short-term circular movements that are common in remote Australia.

While explanation for this anomaly is most likely to be found in respondent error associated with the nature of the NATSISS question and the manner in which it was interpreted, even this is perplexing because previous critiques of census data have pointed to the inappropriateness of applying 'usual residence' concepts for measuring movement among populations that live as much in an 
area as a single place (Morphy 2002: 44-55). However, the NATSISS does not refer to usual residence, preferring instead to talk of the number of dwelling/houses/places 'lived in' which would seem to be a less ambiguous construct - although it does raise the issue of what 'lived in' actually means.

Along with differentials in spatial mobility, the reported data also show clear differences in the propensity to move across a range of social, economic and cultural characteristics that are selected here for their likely association with movement propensity. As indicated by the age-standardised point estimates for each of these variables in Table 5.1, and by the associated 95 per cent confidence interval, these differences tend to reduce for some characteristics and increase for others once the differences in age composition between the categories are controlled for. In some instances, the standardisation procedure even alters the relative balance of variables. For example, the unadjusted migration rate among married people was lower than for those not married, but higher for the standardised result. Overall, the results reveal that movement propensities vary widely around the national average of 30.9 per cent according to the different variables.

Table 5.1. Social, economic and geographic differentials in movement propensity

\begin{tabular}{|c|c|c|c|c|}
\hline \multirow[b]{3}{*}{ Background variable } & \multirow[b]{3}{*}{ Reported } & \multicolumn{3}{|c|}{ Mobility rate $\%$} \\
\hline & & \multicolumn{3}{|c|}{ Age-standardised } \\
\hline & & Point estimate & $95 \%$ lower bound & $95 \%$ upper bound \\
\hline Total & 30.9 & 30.9 & 28.9 & 32.9 \\
\hline \multicolumn{5}{|l|}{ Sex } \\
\hline Males & 30.5 & 30.3 & 27.5 & 33.1 \\
\hline Females & 31.2 & 30.8 & 28.1 & 33.5 \\
\hline \multicolumn{5}{|l|}{ Marital status } \\
\hline Married & 27.6 & 34.6 & 31.7 & 37.5 \\
\hline Not married & 33.7 & 32.2 & 29.5 & 34.9 \\
\hline \multicolumn{5}{|l|}{ Labour force status } \\
\hline Unemployed & 45.4 & 41.1 & 35.1 & 47.1 \\
\hline Not in labour force & 29.6 & 30.7 & 27.6 & 33.8 \\
\hline Employed & 27.6 & 27.6 & 24.8 & 30.4 \\
\hline Public & 22.4 & 24.3 & 18.5 & 30.1 \\
\hline Private & 29.6 & 29.3 & 25.0 & 33.6 \\
\hline CDEP & 28.0 & 26.9 & 21.2 & 32.6 \\
\hline \multicolumn{5}{|l|}{ Education } \\
\hline Post-school & 31.5 & 39.0 & 33.8 & 44.2 \\
\hline Yr 11 and 12 & 37.5 & 32.6 & 28.0 & 37.2 \\
\hline Yr 10 & 32.0 & 29.3 & 25.2 & 33.4 \\
\hline Yr 9 or below & 25.9 & 28.6 & 25.3 & 31.9 \\
\hline \multicolumn{5}{|l|}{ Training } \\
\hline Attended & 34.0 & 30.9 & 26.9 & 34.9 \\
\hline Not attended & 30.8 & 29.5 & 27.3 & 31.7 \\
\hline
\end{tabular}


Table 5.1. (continued)

\begin{tabular}{|c|c|c|c|c|}
\hline \multirow[b]{3}{*}{ Background variable } & \multirow[b]{3}{*}{ Reported } & \multicolumn{3}{|c|}{ Mobility rate $\%$} \\
\hline & & \multicolumn{3}{|c|}{ Age-standardised } \\
\hline & & Point estimate & $95 \%$ lower bound & $95 \%$ upper bound \\
\hline \multicolumn{5}{|l|}{ Housing tenure } \\
\hline Owner & 20.6 & 22.1 & 18.8 & 25.4 \\
\hline Private rental & 52.0 & 47.1 & 41.9 & 52.3 \\
\hline Public rental & 32.9 & 31.6 & 27.8 & 35.4 \\
\hline Community & 25.6 & 25.2 & 21.2 & 29.2 \\
\hline \multicolumn{5}{|l|}{ Place of residence } \\
\hline On homeland & 27.2 & 27.9 & 23.6 & 32.2 \\
\hline Not on homeland & 31.9 & 31.5 & 28.7 & 34.3 \\
\hline $\begin{array}{l}\text { Does not know or } \\
\text { recognise homeland }\end{array}$ & 32.0 & 30.6 & 26.9 & 34.3 \\
\hline \multicolumn{5}{|l|}{$\begin{array}{l}\text { Neighbourhood } \\
\text { problems }\end{array}$} \\
\hline Has problems & 26.5 & 26.0 & 23.1 & 28.9 \\
\hline $\begin{array}{l}\text { Does not have } \\
\text { problems }\end{array}$ & 34.2 & 34.1 & 31.5 & 36.7 \\
\hline \multicolumn{5}{|l|}{ Remoteness } \\
\hline Major cities & 31.5 & 30.9 & 27.2 & 34.6 \\
\hline Inner regional & 36.0 & 36.2 & 31.3 & 41.4 \\
\hline Outer regional & 30.0 & 30.8 & 26.4 & 35.2 \\
\hline $\begin{array}{l}\text { Remote ( } \& \text { very } \\
\text { remote) }\end{array}$ & 27.2 & 27.4 & 23.6 & 31.2 \\
\hline \multicolumn{5}{|l|}{ Health status } \\
\hline Excellent & 28.8 & 24.9 & 20.3 & 29.5 \\
\hline Very good & 32.5 & 29.9 & 26.0 & 33.8 \\
\hline Good & 32.7 & 32.6 & 29.0 & 36.2 \\
\hline Fair & 30.4 & 36.8 & 31.5 & 42.1 \\
\hline Poor & 22.7 & 30.8 & 22.9 & 38.7 \\
\hline
\end{tabular}

Source: Customised cross-tabulations from the 2002 NATSISS RADL

Although this bi-variate analysis is highly suggestive, the net effects of each of these independent variables can only be assessed by a multi-variate analysis. For this purpose, we fit a logistic regression with the dependent variable taking the form of 1 if the respondent lived in any other dwellings (or places) in the 12-month period before the survey, and 0 otherwise (see Table 5.2). In this way, the results indicate the effects of all the selected factors simultaneously on the chances of moving or not. The simplest way of summarising this relationship is to examine what happens to these chances for groups of Indigenous people with different characteristics. These changes in movement probability are best measured relative to a hypothetical reference person and the characteristics of the reference person chosen for this purpose are indicated in the note for Table 5.2 . 
Table 5.2. Net effects of socioeconomic, spatial and household characteristics on Indigenous mobility: logistic regression results, 2002 NATSISS $^{a}$

\begin{tabular}{|c|c|}
\hline Background variables & Odds of mobility \\
\hline Female & 0.999 \\
\hline Not married & $1.189^{b}$ \\
\hline \multicolumn{2}{|l|}{ Labour force status/sector } \\
\hline Unemployed & $2.737^{\mathrm{b}}$ \\
\hline Not in labour force & $1.841^{\mathrm{b}}$ \\
\hline Private & $1.441^{\mathrm{b}}$ \\
\hline CDEP & $1.532^{b}$ \\
\hline \multicolumn{2}{|l|}{ Educational attainment } \\
\hline Post school & $1.109^{b}$ \\
\hline Yr 11 and 12 & $1.319^{b}$ \\
\hline Yr 9 or below & $0.739^{b}$ \\
\hline Not attended vocational training & $0.753^{b}$ \\
\hline \multicolumn{2}{|l|}{ Housing tenure } \\
\hline Owner & $0.558^{b}$ \\
\hline Private rental & $2.16^{b}$ \\
\hline Community & $0.743^{b}$ \\
\hline \multicolumn{2}{|l|}{ Place of residence } \\
\hline Lives on homeland & $0.895^{b}$ \\
\hline Does not know or recognise homeland & 0.998 \\
\hline Problems identified in neighbourhood & $0.663^{b}$ \\
\hline \multicolumn{2}{|l|}{ Remoteness classification } \\
\hline Major cities & $1.051^{\mathrm{b}}$ \\
\hline Inner regional & $1.242^{b}$ \\
\hline Remote/very remote & $1.258^{b}$ \\
\hline \multicolumn{2}{|l|}{ Self-reported health status } \\
\hline Excellent & $0.842^{b}$ \\
\hline Good & $1.026^{b}$ \\
\hline Fair & 1.006 \\
\hline Poor & 0.686 \\
\hline Model intercept & 0.331 \\
\hline
\end{tabular}

a. Reference person is defined as: male, married, employed in the public sector, has Year 10 education, lives in public rental housing, does not live on homeland, neighbourhood has problems, and resident in an outer regional location. The results are not sensitive to the choice of the characteristics of the reference person.

b. Statistically significant at the $5 \%$ level.

Source: 2002 NATSISS RADL

These results indicate that marginal labour force status is the biggest predictor of mobility. After removing the effects of other variables, there is a significant underlying pattern of higher mobility among those unemployed or not in the labour force compared to those employed. When this is controlled for by sector of employment, the chances of movement are seen to be greater among private sector and CDEP workers compared to public sector workers. As for educational attainment, a gradient of increased mobility with higher educational attainment is evident. This is strengthened by the related result that non-attendance in a vocational training course has a negative effect on mobility. 
Housing tenure is another key variable with much higher chances of movement among those in private rental dwellings, while home ownership and community rental serve to depress mobility. Contrary to expectation, respondents resident in neighbourhoods with perceived social problems are far less likely to move, thereby negating what might have been viewed as a push factor and probably reflecting limitations on residential choice. Other findings related to location appear contradictory. For example, residence on homeland is negatively associated with mobility, while remote and very remote location increases the chances of movement. One possibility is that the latter observation reflects the amalgamation of responses from both non-remote and remote non-community sample forms, whereas the former is based on remote community sample data. Finally, self-assessed health status is interesting, as this deflates mobility at extremes of the range, though no doubt for quite different reasons - one due to choice, and the other due to incapacity.

\section{Reasons for movement}

Respondents to the 2002 NATSISS aged 15-64 years were asked to indicate the main reason for their last move. Answers to this question are grouped into four broad categories: housing, family, employment and accessibility (to services), and while this provides for some comparison with findings from the former $A B S$ Internal Migration Survey, this is only true for the housing and employment categories. From Table 5.3, it is clear that factors associated with family and housing dominate in the calculus of mobility decision-making. Among the family reasons provided, the single largest sub-category was a desire to be close to family and friends. This is consistent with repeated findings from case studies of Indigenous mobility that stress the importance of kin location in shaping the frequency and pattern of mobility (Gale \& Wundersitz 1982; Taylor \& Bell 2004: 20-21; Young \& Doohan 1989).

Table 5.3. Reasons for last move by age group: 2002 NATSISS

\begin{tabular}{lrrrrrr}
\hline \multirow{2}{*}{$\begin{array}{l}\text { Reason for } \\
\text { last move }\end{array}$} & $15-24$ & $25-34$ & $35-44$ & $45-64$ & All & $\begin{array}{r}\text { Estimated } \\
\text { population } \\
\text { (no.) }\end{array}$ \\
\cline { 2 - 6 } & & 35.4 & 30.8 & 38.2 & 38.2 & 32400 \\
\hline Family & 45.5 & 39.8 & 38.3 & 33.3 & 33.3 & 28400 \\
Housing & 25.4 & 9.2 & 13.3 & 10.9 & 10.9 & 9300 \\
Employment & 12.6 & 2.4 & 2.6 & 3.3 & 3.3 & 2800 \\
Accessibility & 4.4 & 12.9 & 15.0 & 14.0 & 14.0 & 11900 \\
Other & 11.7 & 0.4 & 0.0 & 0.2 & 0.2 & 200 \\
Don't know & 0.3 & &
\end{tabular}

Source: Customised cross-tabulations from the 2002 NATSISS MURF

As for housing, once again the impact of reliance on rental housing has been highlighted in the literature as an important factor in stimulating Indigenous mobility (Gray 2004), although the results of the NATSISS multi-variate analysis suggest that this is especially so for those in private rental accommodation. The 
overall level of housing reported reasons (33\%) is similar to the 29 per cent reported by the general population in 1987, although in the latter case this was predominantly for home purchase (ABS 1987: 13). Of particular note in Table 5.3 is the fact that the estimated numbers moving for employment reasons is relatively low, although this is not much lower than the 14 per cent reported for the total population in the 1987 ABS survey. Likewise, movement to access services appears very limited, which is surprising given the spatial separation of many Indigenous population clusters from basic services such as high schools, hospitals, banks, shops, and government offices (Taylor 2002). Although the category 'other' is equal in size to employment and access reasons combined, it is not clear what this category comprises.

\section{Conclusion}

The 2002 NATSISS provides the first survey data on Indigenous residential mobility indicating the propensity to move with reasons for doing so. Brief analysis of these data confirms many of the findings from previous census-based analysis: that the probability of movement peaks among young adults, is similar overall for males and females, is higher for single people and especially high among the unemployed, greater for those in private rental dwellings, and lowest in remote areas. Among the new findings are factors that tend to deflate mobility. These include low educational attainment, home ownership, residence in community housing, residence on their homeland, living in an area with neighbourhood problems, and outer regional location. Also new is the insight that CDEP employment does not dampen movement propensity as previously suggested (Taylor \& Bell 1996b). While this much can be gleaned, and while further outcomes and relationships will no doubt be established, even the preliminary findings presented here raise a number of issues regarding the utility and interpretation of NATSISS data on mobility.

First of all is the surprising outcome that the overall propensity to move is only marginally higher than reported in the census, and that in line with the census, movement rates are lowest in the Northern Territory and remote areas generally. So pervasive is the observed fact of residential movement in the daily, fortnightly, seasonal and annual round of Indigenous social and economic life in remote Australia, as elsewhere in the country, that ethnographers have been strained to describe it using evocative terms. These include beats, runs, lines, floaters, visitors, concertina households, or multi-locale relationships (Taylor \& Bell 2004). If the 2002 NATSISS fails to reflect the manifest intensity of population movement in remote areas, then questions naturally focus on non-sampling error and, in particular, how the notion 'lived in' might have been presented by interviewers and interpreted by respondents. Having an open-ended question as in the NATSISS is potentially valuable for capturing short-term and repeat movement, 
but without spatial, temporal, and conceptual structure it can descend into ambiguity.

This brings us to the purpose of a mobility question in a survey such as the NATSISS. In pressing the case, many agencies in submissions to the ABS highlighted the likely impact of mobility on their portfolio areas of concern. If there was ever an expectation that the NATSISS might measure the spatial impact of population movement for the purpose of planning service requirements (the most useful insight from a policy perspective) then this was ill-informed. One assumes, however, that more abstract higher-order questions were in mind, such as those answerable by multi-variate analysis. But again, when we are dealing with movement defined in such a way that it that could be for one night next door as opposed to 11 months across the continent, or from Kintore to Alice Springs instead of Newcastle to Sydney, then structurally - and policy-wise - we are dealing with very different types of mobility that remain totally undifferentiated in the NATSISS. Having said that, further work could be done to isolate sub-groups in the survey population that present potential interest for policy (such as those who indicated employment reasons for movement, or particular difficulties with housing), and their characteristics and behavioural attributes could be explored in more detail. However, much of this is speculative after the event and, as with all such surveys, clear specification of the answers to be addressed by end-users is essential for optimal design.

If we turn to the actual reasons for movement provided by respondents, these conflict (to some degree) with the findings of the multi-variate analysis which highlights structural (economic) factors such as unemployment and private rental housing as key predictors of movement. It is also the case that accessibility to services scores very low as a reason for movement, which is contrary to the experience of many Indigenous people who have to move in order to access basic services such as health care, schooling, training, banking or shopping. The fact is, separating out reasons for mobility is never easy given the multi-faceted purpose and unpredictable nature of many journeys - for example, what may have started out as a shopping expedition to town can turn out to be an extended stay with relatives (Young \& Doohan 1989). Nonetheless, it is interesting that Indigenous people choose to emphasise social over economic factors (such as employment), while many housing reasons (such as overcrowding and wanting a bigger house) can be viewed as both social and economic. This emphasis on social factors is consistent with much of the ethnographic research on mobility that underscores the role of kinship networks in directing population flows, even if the primary purpose might be job search or housing (Gale 1972; Gale \& Wundersitz 1982; Gray 2004). 